\title{
Anaemia Management in Non-Dialysis Chronic Kidney Disease: Flexibility of Target to Target Stability?
}

\author{
Luca De Nicola Roberto Minutolo Giuseppe Conte \\ Nephrology Division, Second University of Naples, Naples, Italy
}

\section{Key Words}

Anaemia $\cdot$ Epoetin $\cdot$ Chronic kidney disease $\cdot$ Haemoglobin variability $\cdot$ End-stage renal disease

\begin{abstract}
International clinical practice guidelines have recently recognized for the first time the concrete difficulty of keeping chronic kidney disease (CKD) patients within the narrow haemoglobin $(\mathrm{Hb})$ target recommended of 11-12 g/dl (110-120 $\mathrm{g} / \mathrm{l}$ ) because of the variability of individual patient $\mathrm{Hb}$ levels. This emerging clinical problem has been the topic of several editorials that, however, exclusively focused on haemodialysis patients. Recently, 3 retrospective studies have been published on $\mathrm{Hb}$ variability in non-dialysis CKD. The studies which overall included more than 6,000 patients showed that $\mathrm{Hb}$ variability in non-dialysis CKD is greatly prevalent and is associated with a worse cardiorenal outcome. This minireview summarizes the results and limits of these studies and discusses the potential implications for clinical practice.

Copyright $\odot 2010$ S. Karger AG, Basel
\end{abstract}

The Anaemia Working Group of the European Renal Best Practice (ERBP) has recently published a position statement on management of renal anaemia [1]. This document extends to European nephrologists the last

\section{KARGER}

Fax +41613061234 E-Mail karger@karger.ch www.karger.com
(C) 2010 S. Karger AG, Base

$1660-2110 / 10 / 1144-0236 \$ 26.00 / 0$

Accessible online at:

www.karger.com/nec
KDOQI recommendations on haemoglobin $(\mathrm{Hb})$ target [2] updated in September 2007 because of the new evidence of the potential harm deriving from therapy with erythropoiesis-stimulating agents (ESA) aimed at complete normalization of $\mathrm{Hb}$ levels [3]. Interestingly, both documents recognize, for the first time, the concrete difficulty of keeping patients within the narrow $\mathrm{Hb}$ target window recommended of 11-12 g/dl (110-120 g/l) because of the intrapatient $\mathrm{Hb}$ variability (or cycling of individual patient $\mathrm{Hb}$ levels). This phenomenon, defined as the degree by which repetitive measures of $\mathrm{Hb}$ vary in the same subject over time, cannot be attributed to laboratory flaws because of the relatively low coefficient of variation in $\mathrm{Hb}$ testing $[4,5]$, and it is distinct from the expected interindividual variability.

$\mathrm{Hb}$ variability has recently emerged as hot topic in nephrology. Various editorials have analyzed the large body of data on $\mathrm{Hb}$ fluctuations, but exclusively in the haemodialysis (HD) setting, including the most recent one by Kalantar-Zadeh and Aronoff [6].

\section{Hb Variability in Non-Dialysis Chronic Kidney Disease}

Only a few studies have evaluated $\mathrm{Hb}$ variability in non-dialysis chronic kidney disease (ND-CKD) patients [7-9]. This is in stark contrast with the observation that 
the size of the anaemic patient population is at least 10fold greater in ND-CKD versus HD [10, 11]. Interestingly, in a multicentric survey of ND-CKD patients regularly followed in 26 Italian renal clinics, $52 \%$ of ESA-treated patients had $\mathrm{Hb}$ values $<11 \mathrm{~g} / \mathrm{dl}(110 \mathrm{~g} / \mathrm{l})$ with standard deviations of $\mathrm{Hb}$ ranging from 1.5 to $1.8 \mathrm{~g} / \mathrm{dl}$ (15-18 g/l) from CKD stage 3-5 [12]. These findings, which resemble the discrepancy between ESA treatment and Hb outcome previously observed in HD [13, 14], suggest inadequate ESA therapy and high degrees of interpatient $\mathrm{Hb}$ variability in ND-CKD. To specifically address intrapatient $\mathrm{Hb}$ variability, we recently reviewed the clinical data obtained from 1,198 visits during the first year of ESA treatment in $137 \mathrm{ND}$-CKD patients [9]. Varying $\mathrm{Hb}$ was found in $85.3 \%$ with downward changes in most cases (table 1). These figures have been confirmed by Boudville et al. [8] in a multicentre study of 6,165 ND-CKD patients, where $\mathrm{Hb}$ variability was detected in $73 \%$ of patients undergoing maintenance ESA therapy.

Interestingly, in normal subjects the individual variation of $\mathrm{Hb}$ levels occurs within the range of normal values and generally does not exceed $1 \mathrm{~g} / \mathrm{dl}(10 \mathrm{~g} / \mathrm{l})$ [15, 16]. Maintenance of steady $\mathrm{Hb}$ levels is indeed mandatory to ensure consistent and adequate oxygen delivery to tissues. Conversely, with $\mathrm{Hb}$ cycling, oxygen delivered to tissues may fluctuate, leading to repeated episodes of relative ischaemia that could finally result in organ dysfunction or injury [6].

The detrimental effects of $\mathrm{Hb}$ fluctuations below the normal range may therefore become critical in conditions characterized by chronic hypoxia. In this regard, it is interesting to note that the constant maintenance of $\mathrm{Hb}$ levels above $11 \mathrm{~g} / \mathrm{dl}(110 \mathrm{~g} / \mathrm{l})$ is already recommended by cardiologists in patients experiencing myocardial infarction and in those with heart failure $[17,18]$. Similar recommendations probably apply to CKD. The majority of adults with moderate CKD, in fact, have coronary heart disease or risk equivalents and a high incidence of ischaemic cardiovascular events [12, 19-21]. While these observations support the need of $\mathrm{Hb}$ values steadily between 11 and $12 \mathrm{~g} / \mathrm{dl}$ (110 and $120 \mathrm{~g} / \mathrm{l})$ to improve patient survival, it is possible to hypothesize benefits of stability of target $\mathrm{Hb}$ levels also in terms of nephroprotection. Indeed, recent studies have recently re-emphasized the role of chronic hypoxia in the tubulointerstitium as a final common pathway to end-stage renal disease (ESRD) $[22,23]$. Specifically, the rarefaction of peritubular capillaries, typical in CKD, impairs oxygen diffusion and supply to tubular and interstitial cells leading to apoptosis or epithelial-mesenchymal
Table 1. Distribution of $137 \mathrm{ND}$-CKD patients according to the pattern of individual $\mathrm{Hb}$ variability during the 1st year of ESA therapy (modified from [9])

\begin{tabular}{lc}
\hline $\mathrm{Hb}, \mathrm{g} / \mathrm{dl}^{1}$ & Prevalence, \% \\
\hline Constantly at $11-13$ & 9.5 \\
Constantly $>13$ & 0.7 \\
Constantly $<11$ & 4.4 \\
Fluctuating from $11-13$ to $<11$ & 48.9 \\
Fluctuating from $11-13$ to $>13$ & 16.0 \\
Fluctuating from $<11$ to $>13$ & 20.4 \\
\hline
\end{tabular}

${ }^{1}$ To convert into SI units (g/l), multiply by 10 .

transdifferentiation; this in turn exacerbates fibrosis and chronic hypoxia, setting a vicious cycle whose end point is ESRD. In this picture, ensuring a stable correction of renal anaemia that is a main factor hindering oxygen delivery may contribute to retarding progression of renal fibrosis.

Such a theoretical background is supported by the outcome analyses of the studies on $\mathrm{Hb}$ variability in NDCKD. Boudville et al. [8] evidenced in their large cohort of ND-CKD patients a $30 \%$ increment in the risk of death per $1 \mathrm{~g} / \mathrm{dl}(10 \mathrm{~g} / \mathrm{l})$ of residual standard deviation of $\mathrm{Hb}$, which is a recognized measure of $\mathrm{Hb}$ variability [6]. When patients were divided into categories of $\mathrm{Hb}$ variability, with the reference group constituted by patients with $\mathrm{Hb}$ constantly at $11-13 \mathrm{~g} / \mathrm{dl}(110-130 \mathrm{~g} / \mathrm{l})$, the greatest association with mortality was found for the subgroup of patients with $\mathrm{Hb}$ steadily below $11 \mathrm{~g} / \mathrm{dl}(110 \mathrm{~g} / \mathrm{l})$ and for patients with $\mathrm{Hb}$ fluctuating from 11-13 g/dl (110-130 g/l) to below $11 \mathrm{~g} / \mathrm{dl}(110 \mathrm{~g} / \mathrm{l})$. Conversely, no significant increase in mortality risk was found for patients with $\mathrm{Hb}$ steadily above $13 \mathrm{~g} / \mathrm{dl}(130 \mathrm{~g} / \mathrm{l})$. The association between $\mathrm{Hb}$ variability and mortality was still significant even after adjustment for absolute $\mathrm{Hb}$ values and $\mathrm{Hb}$ trend (intercept and slope, respectively). Similarly, we found in our cohort that the risk of renal death (death or ESRD) was $58 \%$ lower in patients who spent almost the entire 1st year of ESA therapy with an $\mathrm{Hb} \geq 11 \mathrm{~g} / \mathrm{dl}(110 \mathrm{~g} / \mathrm{l})$ with respect to those who maintained these levels for only 3 months [7]. Nonetheless, it is important to underline that, as in the case of the HD setting [6], the available data on $\mathrm{Hb}$ cycling and outcomes in ND-CKD, being all associative and having been obtained in retrospective analyses, cannot prove causal relationship.

Nephron Clin Pract 2010;114:c236-c241 


\section{Therapeutic Perspectives}

While identification of therapeutic strategies aimed at limiting $\mathrm{Hb}$ variability certainly needs to be explored by interventional studies, knowledge of the potential determining factors in daily practice represents a first critical step. In HD patients, proposed determinants of $\mathrm{Hb}$ variability are multiple and often hardly modifiable, such as cycling variation of fluid status, pre-existing co-morbid conditions, acute intercurrent infections and chronic inflammation [6, 24]. In this setting, patient characteristics account for very little $\mathrm{Hb}$ variability, as suggested by the very low $\mathrm{R}^{2}$ of the regression model (0.019) used by Yang et al. [25] to identify potential predictors of increased $\mathrm{Hb}$ variability in a large HD population.

This may change in the non-dialysis setting where the burden of unmodifiable factors is less evident. Indeed, Boudville et al. [8] found that use of ESA, younger age, variability of glomerular filtration rate and lower albumin levels were all predictors of $\mathrm{Hb}$ variability with an $\mathrm{R}^{2}$ of the regression model of 0.113 ; this value is definitely greater than that reported above for HD patients but it is still low, meaning that factors other than those considered accounted for the major part of the $\mathrm{Hb}$ variability [8].

More insights into the potential determinants of this phenomenon were provided in the 2 studies by our group. In our ND-CKD cohort, basal glomerular filtration rate and $\mathrm{Hb}$ levels at the beginning of ESA therapy were directly and independently associated with the length of time spent with $\mathrm{Hb}$ at target (time in target) in the subsequent year of treatment [7]. These data suggest that positive effects on $\mathrm{Hb}$ stability may be attributed to the timely intervention with ESA. It is reasonable to hypothesize that the earlier ESA therapy is started, the higher are the levels of endogenous epoetin, which may contribute to ensuring steadiness of $\mathrm{Hb}$ target levels during exogenous ESA administration. Interestingly, a similar correlation with time in target was also found for first epoetin dose and iron supplementation. Overall, these observations suggest a main role for therapeutic intervention. In fact, inadequate epoetin levels, either endogenous or exogenous, are associated with shorter survival of red cells, while a lack of iron can lead to haematopoietic deficiencies [26-28]. Interestingly, the 2 phenomena may also be interrelated. Recent studies have in fact evidenced that serum levels of hepcidin, an inhibitor of iron release from reticulo-endothelial cells and of iron uptake in the gut, are elevated in NDCKD [29]; more importantly, increased hepcidin, be- sides contributing to abnormal iron regulation, might also directly inhibit erythroid progenitor proliferation and survival when epoetin levels are low [30]. Therefore, it is possible to hypothesize that low levels of circulating epoetin may activate adverse mechanisms such as neocytolysis and hepcidin transcription leading to a deficient haematopoietic response to ESA that interferes with $\mathrm{Hb}$ stability. Indeed, in our study, the first mean ESA doses were in the low range, that is $25 \mu \mathrm{g} /$ week for darbepoetin and 4,500 IU/week for epoetin [7]. More importantly, nephrologists generally did not uptitrate doses in the subsequent control visits even when they recognized that the $\mathrm{Hb}$ goal had not been met. This 'conservative' attitude may extend to other renal clinics in the multicentric survey in Italy described above [12]. In fact, the median ESA dose during the maintenance phase of ESA therapy was $23 \mu \mathrm{g} /$ week for darbepoetin and 4,000 IU/week for epoetin.

Therapeutic inertia in the use of ESA, i.e. the provider's failure to modify the ESA dose despite recognition that treatment goals are unmet, therefore, emerges as a potential determinant of $\mathrm{Hb}$ cycling in ND-CKD. This hypothesis was supported in our most recent study, showing that a change of ESA dose occurred in only half of control visits where it was expected on the basis of guidelines' recommendations, and that higher degrees of therapeutic inertia were associated with greater $\mathrm{Hb}$ variability, characterized by downward fluctuations in most cases as well as the risk of renal death [9]. This study also confirmed the role of the first ESA dose. Indeed, only a minority of patients responded adequately to the first 'low' dose with an increase in the $\mathrm{Hb}$ level from about 10 to $\geq 11 \mathrm{~g} / \mathrm{dl}$ within the first 2 months and maintenance of target levels thereafter. Conversely, most patients hardly achieved and maintained the $\mathrm{Hb}$ target despite similar ESA dosing. Indeed, physicians did not increase the ESA dose in all patients, that is in patients who showed greater responsiveness to ESA, those who required any or only minor changes of ESA dosages and in 'low responder' patients who, conversely, required an increment of the ESA dose. In the latter group, the reduction of endogenous epoetin levels below erythropoietic threshold and the ensuing activation of hepcidin pathway and neocytolysis may have contributed to the greater rate of downward $\mathrm{Hb}$ fluctuations.

The different $\mathrm{Hb}$ responsiveness to ESA could not be ascribed to the so-called ESA resistance because no difference was found in the prevalence of the main causes of this phenomenon (co-morbidities, iron deficiency, hyperparathyroidism, impaired nutrition, inflammatory 
status, and administration of renin-angiotensin system inhibitors). Therefore, it is possible to hypothesize that the response to ESA was, at least in part, of biologic nature and independent of the recognized factors of ESA resistance.

The observational findings available at this moment on the determinants of $\mathrm{Hb}$ variability do not allow the definition of interventions specifically aimed at improving $\mathrm{Hb}$ stability; however, these data do actually reinforce the guidelines' recommendations on management of renal anaemia $[1,2]$. Best treatment in terms of a timely start of ESA therapy, iron supplementation and 'active' monitoring of patients may in fact not only allow the achievement of $\mathrm{Hb}$ target levels but also permit a greater steadiness of these levels during the maintenance phase of ESA therapy (table 2). Nowadays, however, scarce implementation of the guidelines in nephrology is unfortunately frequent and multifaceted $[12,31]$. In the specific case of anaemia treatment in NDCKD patients, it is possible to hypothesize that physicians, being overwhelmed by the multiple interventions required in these patients, often feel more confident in giving a fixed low dose of ESA, even if not 'fully' efficacious. This position is probably further strengthened by the narrow target range now recommended, the concerns about $\mathrm{Hb}$ overshooting, as well as by the recognition of the potential negative effects of the use of ESA at a high dose (>10,000 IU/week) [32].

\section{Conclusions}

In $\mathrm{ND}-\mathrm{CKD}, \mathrm{Hb}$ variability is greatly prevalent and associated with worse cardiorenal outcome. However, the data so far collected are limited and of an observational nature. Further investigation is therefore needed prior to drawing any firm conclusion. Nevertheless, ob-
Table 2. Potential interventions to improve $\mathrm{Hb}$ stability in NDCKD

Regular monitoring of renal function, $\mathrm{Hb}$ and iron status

Correct the main modifiable factors affecting erythropoiesis (hyperparathyroidism, impaired nutrition, inflammatory status)

Start ESA when $\mathrm{Hb}<11 \mathrm{~g} / \mathrm{dl}(110 \mathrm{~g} / \mathrm{l})$ in 2 consecutive controls

Iron supplementation when ferritin $<100 \mathrm{ng} / \mathrm{ml}$ or transferrin saturation $<20 \%$

Target therapy to $\mathrm{Hb} 11-12 \mathrm{~g} / \mathrm{dl}(110-120 \mathrm{~g} / \mathrm{l})$ while accepting higher $\mathrm{Hb}$ levels for a limited period of time

Change ESA dose on the basis of $\mathrm{Hb}$ response also in the absence of recognized factors of ESA resistance

servational data are hypothesis-generating and essential to design prospective interventional studies that take into account $\mathrm{Hb}$ variability. In this regard, it is intriguing to hypothesize that this phenomenon may explain, at least in part, the contradictory results in the relationship between anaemia correction and patient outcome reported in the most recent randomized trials in ND-CKD $[3,33]$.

While awaiting more studies on $\mathrm{Hb}$ variability, nephrologists should follow the latest recommendation of the ERBP and KDOQI on the need of maintaining flexibility in the medical decision $[1,2]$. As recently emphasized, in fact, clinical guidelines are supposed to be guides, not rules, and tailoring of therapy is a critical aspect of management because 'one size certainly does not fit all patients' [34]. This concept may be particularly important for the optimal management of CKD-related anaemia because flexibility is likely essential to obtain adequate steadiness of target $\mathrm{Hb}$ levels.

\section{References}

Locatelli F, Covic A, Eckardt KU, Wiecek A, Vanholder R, ERA-EDTA ERBP Advisory Board: Anaemia management in patients with chronic kidney disease: a position statement by the Anaemia Working Group of European Renal Best Practice (ERBP). Nephrol Dial Transplant 2009;24:348-354.

$\checkmark 2$ KDOQI: KDOQI clinical practice guideline and clinical practice recommendations for anemia in chronic kidney disease, 2007 update of hemoglobin target. Am J Kidney Dis 2007;50:471-530.
Singh AK, Szczech L, Tang KL, Barnhart H, Sapp S, Wolfson M, Reddan D, CHOIR Investigators: Correction of anemia with epoetin alfa in chronic kidney disease. N Engl J Med 2006;355:2085-2098.

4 Mohandas N, Kim YR, Tycko DH, Orlik J, Wyatt J, Groner W: Accurate and independent measurement of volume and hemoglobin concentration of individual red cells by light scattering. Blood 1986;68:506-513. 
5 Rosenblit J, Abreu CR, Szterling LN, Kutner JM, Hamerschlak N, Frutuoso P, Paiva TR, Ferreira OC Jr: Evaluation of three methods for hemoglobin measurement in a blood donor setting. Sao Paulo Med J 1999;117:108112.

6 Kalantar-Zadeh K, Aronoff GR: Hemoglobin variability in anemia of chronic kidney disease. J Am Soc Nephrol 2009;20:479487.

7 De Nicola L, Conte G, Chiodini P, Cianciaruso B, Pota A, Bellizzi V, Tirino G, Avino D, Catapano F, Minutolo R: Stability of target hemoglobin levels during the first year of epoetin treatment in CKD patients. Clin J Am Soc Nephrol 2007;2:938-946.

$>8$ Boudville N, Djurdjev O, Macdougall I, de Francisco AL, Deray G, Besarab A, Stevens PE, Walker RG, Ureña P, Iñigo P, Minutolo R, Haviv YS, Yeates K, Agüera ML, MacRae JM, Levin A: Hemoglobin variability in nondialysis chronic kidney disease: examining the association with mortality. Clin J Am Soc Nephrol 2009;4:1176-1182.

$\checkmark 9$ Minutolo R, Chiodini P, Cianciaruso B, Pota A, Bellizzi V, Avino D, Mascia S, Laurino S, Bertino V, Conte G, De Nicola L: Epoetin therapy and hemoglobin level variability in nondialysis patients with chronic kidney disease. Clin J Am Soc Nephrol 2009;4:552559.

-10 Coresh J, Selvin E, Stevens LA, Manzi J, Kusek JW, Eggers P, Van Lente F, Levey AS: Prevalence of chronic kidney disease in the United States. JAMA 2007;298:2038-2047.

-11 Astor BC, Muntner P, Levin A, Eustace JA, Coresh J: Association of kidney function with anemia: the Third National Health and Nutrition Examination Survey (1988-1994). Arch Intern Med 2002;162:1401-1408.

$\checkmark 12$ De Nicola L, Minutolo R, Chiodini P, Zamboli P, Zoccali C, Castellino P, Donadio C, Strippoli M, Casino F, Giannattasio M, Petrarulo F, Virgilio M, Laraia E, Di Iorio BR, Savica V, Conte G, Target Blood Pressure Levels in Chronic Kidney Disease (TABLE in CKD) Study Group: Global approach to cardiovascular risk in chronic kidney disease: reality and opportunities for intervention. Kidney Int 2006;69:538-545.

$\checkmark 13$ Locatelli F, Pisoni RL, Akizawa T, Cruz JM, DeOreo PB, Lameire NH, Held PJ: Anemia management for hemodialysis patients: Kidney Disease Outcomes Quality Initiative (K/ DOQI) guidelines and Dialysis Outcomes and Practice Patterns Study (DOPPS) findings. Am J Kidney Dis 2004;44:S27-S33.
4 Collins AJ, Brenner RM, Ofman JJ, Chi EM, Stuccio-White N, Krishnan M, Solid C, Ofsthun NJ, Lazarus JM: Epoetin alfa use in patients with ESRD: an analysis of recent US prescribing patterns and hemoglobin outcomes. Am J Kidney Dis 2005;46:481-488.

15 Ross DW, Ayscue LH, Watson J, Bentley SA: Stability of hematologic parameters in healthy subjects. Intraindividual versus inter-individual variation. Am J Clin Pathol 1988;90:262-267.

16 Dot D, Mirò J, Fuentes-Arderiu X: Withinsubject biological variation of hematological quantities and analytical goals. Arch Pathol Lab Med 1992;116:825-826.

-17 Goodnough LT, Bach RG: Anemia, transfusion, and mortality. N Engl J Med 2001;345: 1272-1273.

18 Groenveld HF, Januzzi JL, Damman K, van Wijngaarden J, Hillege HL, van Veldhuisen DJ, van der Meer P: Anemia and mortality in heart failure patients: a systematic review and meta-analysis. J Am Coll Cardiol 2008; 52:818-827.

19 Sarnak MJ, Levey AS, Schoolwerth AC, Coresh J, Culleton B, Hamm LL, McCullough PA, Kasiske BL, Kelepouris E, Klag MJ, Parfrey P, Pfeffer M, Raij L, Spinosa DJ, Wilson PW, American Heart Association Councils on Kidney in Cardiovascular Disease, High Blood Pressure Research, Clinical Cardiology, and Epidemiology and Prevention: Kidney disease as a risk factor for development of cardiovascular disease: a statement from the American Heart Association Councils on Kidney in Cardiovascular Disease, High Blood Pressure Research, Clinical Cardiology, and Epidemiology and Prevention. Hypertension 2003;42:1050-1065.

$\checkmark 20$ Hyre AD, Fox CS, Astor BC, Cohen AJ Muntner P: The impact of reclassifying moderate $\mathrm{CKD}$ as a coronary heart disease risk equivalent on the number of US adults recommended lipid-lowering treatment. Am J Kidney Dis 2006;49:37-45.

-21 Pereg D, Tirosh A, Shochat T, Hasdai D; Metabolic, Lifestyle and Nutrition Assessment in Young Adults (MELANY) Investigators: Mild renal dysfunction associated with incident coronary artery disease in young males. Eur Heart J 2008;29:198-203.

22 Nangaku M: Chronic hypoxia and tubulointerstitial injury: a final common pathway to end-stage renal failure. J Am Soc Nephrol 2006;17:17-25.

23 Fine LG, Norman JT: Chronic hypoxia as a mechanism of progression of chronic kidney diseases: from hypothesis to novel therapeutics. Kidney Int 2008;74:867-872.
24 Bellizzi V, Minutolo R, Terracciano V, Iodice C, Giannattasio P, De Nicola L, Conte G, Di Iorio BR: Influence of the cyclic variation of hydration status on hemoglobin levels in hemodialysis patients. Am J Kidney Dis 2002; 40:549-555.

25 Yang W, Israni RK, Brunelli SM, Joffe MM, Fishbane S, Feldman HI: Hemoglobin variability and mortality in ESRD. J Am Soc Nephrol 2007;18:3164-3170.

26 Lacombe C, Mayeux P: Biology of erythropoietin. Haematologica 1998;83:724-732.

$\checkmark 27$ Weiss MJ, dos Santos CO: Chaperoning erythropoiesis. Blood 2009;113:2136-2144.

28 Fishbane S: Iron management in nondialysis-dependent CKD. Am J Kidney Dis 2007; 49:736-743

-29 Zaritsky J, Young B, Wang HJ, Westerman M, Olbina G, Nemeth E, Ganz T, Rivera S, Nissenson AR, Salusky IB: Hepcidin - a potential novel biomarker for iron status in chronic kidney disease. Clin J Am Soc Nephrol 2009;4:1015-1016.

$>30$ Dallalio G, Law E, Means RT Jr: Hepcidin inhibits in vitro erythroid colony formation at reduced erythropoietin concentrations. Blood 2006; 107:2702-2704.

-31 Zoccali C, Abramowicz D, Cannata-Andia JB, Cochat P, Covic A, Eckardt KU, Fouque D, Heimburger O, McLeod A, Lindley E, Locatelli F, Spasovski G, Tattersall J, Van Biesen W, Wanner C, Vanholder R, European Best Practice Guidelines, European Renal Best Practice: European best practice quo vadis? From European Best Practice Guidelines (EBPG) to European Renal Best Practice (ERBP). Nephrol Dial Transplant 2008;23: 2162-2166.

>32 Szczech LA, Barnhart HX, Inrig JK, Reddan DN, Sapp S, Califf RM, Patel UD, Singh AK: Secondary analysis of the CHOIR trial epoetin-alpha dose and achieved hemoglobin outcomes. Kidney Int 2008;74:791-798.

33 Pfeffer MA, Burdmann EA, Chen CY, Cooper ME, de Zeeuw D, Eckardt KU, Feyzi JM, Ivanovich P, Kewalramani R, Levey AS, Lewis EF, McGill JB, McMurray JJ, Parfrey P, Parving HH, Remuzzi G, Singh AK, Solomon SD, Toto R; the TREAT Investigators: A trial of darbepoetin alfa in type 2 diabetes and chronic kidney disease. N Engl J Med 2009;361:2019-2032.

34 Shaneyfelt TM, Centor RM: Reassessment of clinical practice guidelines: go gently into that good night. JAMA 2009;301:868-869. 


\section{Editorial Comment}

M. El Nahas, Sheffield

The minireview by De Nicola et al. focuses on the importance of haemoglobin $(\mathrm{Hb})$ variability in pre-dialysis chronic kidney disease (CKD) patients. It re-emphasizes the growing concern relating to $\mathrm{Hb}$ variability and subsequent morbidity and mortality. Up to very recently, attention in the management of anaemia in CKD and endstage renal disease (ESRD) has focused almost exclusively on target $\mathrm{Hb}$ levels. But more recent attention has highlighted the issue of $\mathrm{Hb}$ fluctuations. Cohort studies suggest that $\mathrm{Hb}$ fluctuations may be associated with worse cardiovascular outcomes. Whether this is directly related to the $\mathrm{Hb}$ fluctuations per se or the underlying comorbidities that lead to these fluctuations is difficult to untangle. From past experience, cohort studies in nephrology, including those in the field of anaemia man- agement, were not supported by prospective randomized clinical trials such as CHOIR and CREATE! However, there is little doubt that $\mathrm{Hb}$ fluctuations outside the target range occur frequently in CKD/ESRD patients [1]. Nephrologists need to pay more attention to these fluctuations and optimize their therapeutic response to maintain patients within the target range and minimize wide fluctuations.

\section{Reference}

1 Roche A, Macdougall IC, Walker RG: Haemoglobin fluctuations in patients on haemodialysis treated with ESAs: clinical observations from two centres. Curr Med Res Opin 2009, E-pub ahead of print. 